\title{
NO TODOS LOS CACIQUES FUERON MALLKU. MEDIACIÓN POLÍTICA TRUNCADA EN LOS CORREGIMIENTOS DE PACAJES Y OMASUYOS (AUDIENCIA DE CHARCAS, 1570-1630)
}

\author{
NOT ALL CACIQUES WERE MALLKU. TRUNCATED POLITICAL MEDIATION \\ IN PACAJES AND OMASUYOS CORREGIMIENTOS \\ (AUDIENCIA DE CHARCAS, 1570-1630)
}

\begin{abstract}
Ariel Morrone*
La sistematización del dominio colonial implantada en el Perú durante el gobierno del virrey don Francisco de Toledo (1569-1581) habilitó nuevas instancias de mediación política para los caciques principales y gobernadores de los repartimientos surandinos, devenidos interlocutores válidos en la articulación de una modalidad indirecta de gobierno sobre los colectivos étnicos. Ubicados "entre dos legitimidades", algunos líderes ocuparon posiciones estratégicas del entramado político local, participando de la economía mercantil en plena diversificación, apelando a la justicia colonial en defensa de cargos, derechos y tierras, e incluso acumulando riquezas a título personal. Pero tal no fue el caso de muchos otros caciques que, con menor "potencial gestor" de las economías étnicas, vieron disminuidas sus influencias y sus márgenes de acción. En este artículo nos proponemos rescatar del "olvido documental" a esas figuras de liderazgo minorizado, que no respondieron al patrón historiográfico del "cacique exitoso". Los corregimientos de Pacajes y Omasuyos, dependientes de la ciudad de La Paz (actual Bolivia) constituyen, a nuestro entender, escenarios óptimos para el análisis de los procesos de reconfiguración política, toda vez que sus caciques presentaron una amplia variabilidad de trayectorias que en este artículo recuperamos a partir de una perspectiva comparada.
\end{abstract}

Palabras claves: Cacique, legitimidad, Charcas, liderazgo, dominio colonial.

The systematization of colonial dominion in Perú during the rule of viceroy don Francisco de Toledo (1569-1581) enabled new political mediating instances for Southandean caciques principales y gobernadores (local chiefs), who became valid interlocutors for the articulation of an indirect rule over ethnic groups. Settled "between two legitimaices", some leaders hold strategic positions within local political network, participating in the diversified mercantile economy, appealing at colonial justice in defense of their charges, rights and lands, and even accumulating personal wealth. However, it was not the case for many other caciques with less "managing potential" of ethnic economics, who saw their influences and action scopes diminished. In this paper we focus on those minorized leadership figures, who did not fit into the historiographical pattern of "successful cacique", and to rescue them from "documental oblivion". We understand that Pacajes and Omasuyos corregimientos (rural colonial administrative jurisdiction), dependent of La Paz city (present Bolivia), constitute optimal scenes for political reconfiguration processes, since their caciques showed wide variability of trajectories, which in this paper we recover from a comparative perspective.

Key words: Cacique, legitimacy, Charcas, ethnic leadership, colonial dominion.

\section{Introducción}

La consolidación del orden colonial en el virreinato del Perú a partir del gobierno del virrey don Francisco de Toledo (1569-1581) implicó la sistematización de algunas prácticas de dominación sobre la población nativa. Entre las principales medidas adoptadas por el gobierno colonial, la reconfiguración del patrón de asentamiento nativo mediante la reducción a pueblos de indios, la monetización del tributo, la puesta en marcha de la producción argentífera en el cerro Rico de Potosí y la reglamentación de la mita impactaron de lleno en la posición intermediaria las autoridades étnicas (kuraka o mallku, "caciques" en general), quienes debieron reacomodarse a las nuevas reglas del juego, combinando tradicionales y novedosas prácticas sociales (Stern 1986 [1982]; Saignes 1984; Morong 1999).

En efecto, los caciques andinos habitaron (una vez más) una instancia de mediación entre los distintos niveles del poder imperial y sus grupos parentales de base (ayllu), cuyas bases de reproducción

* Consejo Nacional de Investigaciones Científicas y Técnicas (CONICET), Programa de Historia de América Latina (PROHAL), Instituto de Historia Argentina y Americana "Dr. Emilio Ravignani”, Facultad de Filosofía y Letras, Universidad de Buenos Aires. Buenos Aires, Argentina. Correo electrónico: arielmorri@yahoo.com.ar 
debían garantizar al tiempo que vehiculizaban el dominio hispánico. En tanto "piezas maestras" del gobierno indirecto, tuvieron que enfrentar el pago anual del tributo y la provisión de mano de obra mitaya. En la intermediación política, la legitimidad de estos líderes étnicos fue puesta en juego en más de una oportunidad, toda vez que ambas exacciones impactaban de lleno en el accceso nativo a los recursos (mano de obra, tierra, agua y ganado), condicionando en gran medida las bases de reproducción biológica y social de los ayllu (Spalding 1974:51).

En términos historiográficos, desde la década de 1980 asistimos a la conformación de un paradigma para el análisis de estas figuras de intermediación, que ha indagado en la participación de los caciques andinos en los mercados coloniales, su acceso a la justicia en las distintas instancias locales y regionales (corregimiento de indios, Audiencia) y su relativa adaptación a las pautas culturales del segmento dominante (mestizaje cultural u occidentalización). El estudio de estas estrategias de adaptación y reacomodamiento hicieron énfasis en la legitimidad "externa" del poder étnico, es decir, aquella que provenía de las instancias dominantes de la sociedad colonial. En ese sentido, mucho se ha escrito acerca del "modelo cacical mercantil", tomando como unidad de análisis aquellas experiencias históricas que respondieron "exitosamente" a los desafíos del poder colonial (Platt 1982; Harris et al. 1987; Pease G.Y. 1992; Gisbert 1992; Choque Canqui 1993).

Menor atención ha recibido, empero, la "cara interna" de la legitimidad, aquella emanada de los ayllu que los caciques andinos congregaban y representaban. Las dificultades heurísticas para dar con "la voz de los tributarios" explican, en gran medida, esta relativa "demora" para el abordaje de los avales legitimatorios que los miembros de los ayllu otorgaban a sus líderes, en reconocimiento de sus capacidades tanto materiales como simbólicas y de los pactos de reciprocidad tramados en el parentesco. Del mismo modo, las experiencias de caciques de menor porte y valía, cuya adaptación y reconversión al sistema colonial fueron larvadas, "poco exitosas" o nulas, suelen quedar ocultas tras las sombras de las grandes figuras de liderazgo.

En este trabajo echamos luz sobre estas "zonas ensombrecidas" de la política nativa: la legitimidad interna y los liderazgos truncados. Nuestro escenario serán los corregimientos de Pacajes y Omasuyos,

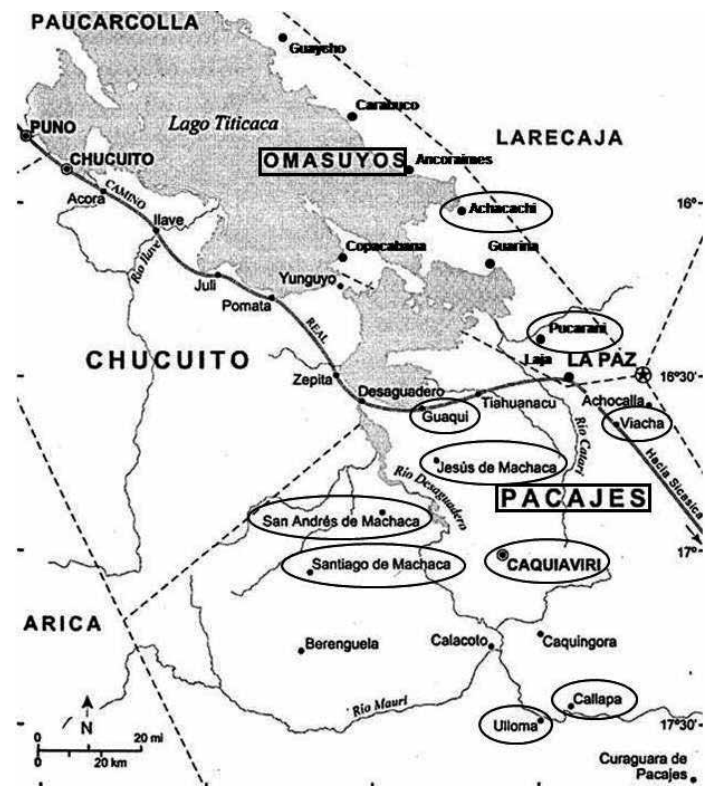

Figura 1. Corregimientos de Pacajes y Omasuyos. Pueblos de reducción mencionados en el texto. Mapa intervenido a partir de Thomson 2006:21.

jurisdicciones administrativas dependientes de la ciudad de Nuestra Señora de La Paz (Audiencia de Charcas, ver Figura 1), entre el último tercio del siglo XVI y las primeras décadas del siglo XVII. El recorte temporal responde a la estructuración del dominio colonial en torno a las reformas toledanas, el auge de la minería potosina y su primera crisis, la fragmentación de las antiguas agrupaciones aymara y el protagonismo de los caciques a nivel del pueblo de reducción. Para ello, analizamos las constricciones del dominio colonial, las prácticas articuladas por las autoridades étnicas y sus efectos al calor de la intermediación política.

Nos interesa trazar el derrotero de las autoridades étnicas de los corregimientos de Pacajes y Omasuyos a partir del estrecho vínculo establecido entre el liderazgo étnico y la territorialidad. Entendemos que el potencial político de los caciques andinos estuvo condicionado, entre otros factores, por su habilidad para definir estrategias de control, defensa y reproducción de las dotaciones de recursos, población y relaciones sociales enmarcadas en diversas áreas geográficas, es decir, para ejercer territorialidad (Sack 1986; Saignes 1987b). En tanto los caciques lograran asegurar la reproducción biológica y social del grupo que encabezaban, sus legitimidades internas no se verían amenazadas a 
pesar de, al mismo tiempo, formar parte del entramado político-institucional colonial a escala local.

En este sentido, las reformas toledanas implicaron un nuevo desafío para los colectivos étnicos y sus autoridades. ¿Hasta qué punto podrían los caciques mantener el control de espacios, recursos y territorios? Los recursos devinieron protagonistas principales del conflicto entre los segmentos nativo y español de la sociedad colonial. Estructurado el mercado colonial en torno al polo minero de Potosí, el drenaje de tierras y ganado a manos españolas alteró su disponibilidad y puso en jaque la legitimidad de los líderes étnicos. De este modo, entre las décadas finales del siglo XVI y la primera mitad del siglo XVII asistimos a una reorganización de los esquemas políticos locales y de los elencos cacicales, cuyas trayectorias distaron de recorrer caminos unificados. ${ }^{1}$

La pérdida de tierras, ya sea por usurpación de hecho o por mecanismos "de derecho" (mercedes, compraventa, composición), y la enajenación de ganado para cumplir con el pago de los tributos fueron factores que deterioraron progresivamente las condiciones de reproducción de los repartimientos surandinos, sobre todo en los casos cuyos caciques no pudieron operar los goznes del sistema colonial. A partir de la década de 1580 , un conjunto de inclemencias climáticas (sequías, heladas y malas cosechas), enfermedades endémicas (viruelas, sarampión, tabardillo) y un creciente ausentismo indígena de carácter "táctico antifiscal" empezaron a socavar el nuevo edificio toledano montado sobre el trabajo y los recursos nativos (Saignes 1987a). El efecto combinado de estos factores redundó en una notoria caída demográfica de la población nativa y en la disminución de la masa tributaria, lo que si bien podría haber contrabalanceado el drenaje de recursos, con el paso de las décadas erosionó en buena medida las condiciones materiales de vida de los grupos étnicos. Analizamos, pues, algunos episodios asociados específicamente al control de ganado (y, en menor medida, de la mano de obra), presentando los desairados casos de aquellos caciques que resolvieron de un modo "no exitoso" (o que no resolvieron) sus disputas por los recursos escasos.

\section{Ganado perdido en el pago de deudas (1591-1610)}

Desde tiempos prehispánicos, los camélidos constituyeron un componente esencial de los sistemas productivos aymara, empleados por las unidades domésticas como medio de transporte y fuente de alimentos, mientras que para las autoridades constituyeron un símbolo de riqueza y poder. El ganado ocupaba un lugar central en la producción y reproducción de un modo de vida pastoril y de los circuitos de intercambio, mediante las redes de tráfico caravanero que cruzaban el espacio altiplánico desde tiempos preincaicos. Asimismo, el Tawantinsuyu tuvo un especial interés en apropiarse del ganado de los grupos lacustres, asignándolo al culto estatal, si bien los mallku pudieron conservar parte de sus rebaños. El control sobre este recurso permitió, a su vez, organizar las caravanas que recorrían los distintos pisos ecológicos, garantizando el intercambio de bienes entre la puna, las sierras, los valles y la costa pacífica, aunque también entre distintas zonas de producción altiplánicas. Tras la conquista española, el ganado ingresó rápidamente en los circuitos mercantiles, utilizándose en un primer momento como bien de cambio y luego como mercancía. Progresivamente, las presiones de la esfera mercantil sobre la economía nativa provocaron la transferencia de recursos ganaderos a manos españolas, sobre todo a partir de la consolidación del gobierno colonial y del establecimiento de matrículas tributarias fijas en dinero (Murra 1999 [1955]; Núñez y Dillehay 1978; Assadourian 1987; Medinacelli 2010). De esta manera, el ganado constituyó un recurso clave en la definición de los márgenes de acción de las autoridades étnicas frente a las exigencias del poder colonial. El manejo de rebaños, tanto dentro de los circuitos redistributivos de los ayllu como en los diversificados mercados surandinos, nos permitirá observar en qué medida los caciques andinos resolvieron el complejo nudo (acaso gordiano) de la intermediación política.

La participación de los grandes caciques andinos en los mercados coloniales se operó por medio del transporte y comercialización de productos tales como el maíz, la coca, el vino y los textiles, a lo largo de rutas de intercambio caravanero que vertebraban la economía surandina: el "espacio del trajín" (Glave 1989). Para nuestra región de estudio, es bien conocido el caso de los caciques Fernández Guarachi de Jesús de Machaca, quienes entre mediados del siglo XVII y mediados del siglo XVIII ocuparon posiciones de gran relevancia en el escenario político regional, en gran medida a partir del control de grandes manadas de llamas y alpacas (Rivera Cusicanqui 1978; Choque Canqui 1987). 
Para ofrecer un contraejemplo de este "caso testigo" de la historiografía andina, presentamos aquí los derroteros de otros caciques del corregimiento de Pacajes menos afamados.

Los pueblos de San Andrés y Santiago de Machaca habían conformado, en tiempos pretoledanos, un único repartimiento, el de Machaca la Grande, bajo administración directa de los oficiales de la Real Hacienda en tanto encomienda real. Para la década de 1580 encontramos al cacique principal de San Andrés, don García Guanaco, articulando negocios en el mercado paceño con el manejo de sus recursos ganaderos y reclamando ante la Audiencia de Charcas en un pleito por tierras. Como contracara, entre 1592 y 1606, otros caciques de San Andrés tuvieron que rematar parte de sus rebaños para obtener el dinero destinado al pago de tributos atrasados, en un contexto de marcada caída demográfica. Asimismo, debieron enfrentar los reveses de los beneficiarios de los remates de los tributos en especie y de sus cobradores. ${ }^{2}$

Las escrituras notariales de Potosí también revelan que en abril de 1591, don Pablo Guanca Ticona y don Sebastián Cacya Pacari, caciques principales de Santiago de Machaca, vendieron 52 llamas a Amador de Fuentes y a Alonso de Herrera, su padre. Los animales debían ser gordos creçidos y escogidos fuera de carache de hedad de tres años, a razón de siete pesos corrientes, los quales an de ser pacaxas puestos en el dicho pueblo de Santiago de Mamañeca. Los compradores tendrían un mes para efectuar el pago de los 364 pesos totales, que los caciques destinarían a pagos que todavía debían a las Cajas Reales. ${ }^{3}$

Por su parte, en febrero de 1606, don Felipe Chocata, cacique principal de Callapa, solicitó al escribano potosino Juan Leal un traslado de un memorial presentado el año anterior por todos los caciques del corregimiento de Pacajes al virrey don Gaspar de Zúñiga y Acevedo, conde de Monterrey. En esa petición los caciques denunciaban a los beneficiarios de los remates, quienes ban luego a sus pueblos a prebenir sea abentaxada en que son gravemente molestados y bexados y sobre que se les hagan camaricos y por estar los mas de los maridos en la mita de Potosi y no tener protector ni administrador las mugeres hijos e hijas todos padecen y se aprovechan de todo lo que ay. ${ }^{4}$

Pero los conflictos por el ganado no se circunscribieron a la relación tributaria. En 1607 el capitán Juan de Ciancas, juez visitador de estancias y obrajes para la jurisdicción de la Audiencia de Charcas, recibió en La Paz las denuncias de dos principales de la parcialidad hanansaya del pueblo de Viacha, Domingo Calli, del ayllu Yrpa, y don Diego Titi Umani, del ayllu Mamani, en contra de nueve propietarios españoles. El principal motivo de denuncia fue la falta de pago de los jornales por los servicios de guarda de ganado que los pastores de Viacha brindaban en las estancias. Sin embargo, ambos principales refirieron otros abusos: castigos físicos (aporreos, azotes y engrillamiento), cobro de multas y sustracción de vestimenta por piezas de ganado muertas o perdidas y empleo en servicio doméstico o trabajo agrícola. ${ }^{5} \mathrm{~A}$ diferencia de las situaciones anteriores, el recurso en pugna no fue el ganado sino la fuerza de trabajo de los pastores afectados a su cuidado, lo que impactaba en última instancia sobre las condiciones de reproducción de los ayllu, el potencial productivo del repartimiento y su capacidad de enfrentar el resto de las exacciones coloniales.

De los episodios hasta aquí reseñados solo los caciques de San Andrés de Machaca resultaron beneficiados por las gestiones ante la justicia colonial. Mientras desconocemos la resolución de la visita del capitán Ciancas en atención a las denuncias de los principales de Viacha, para 1610 don Felipe Chocata de Callapa se encontraba preso en la cárcel pública de La Paz junto a don Pedro Nina, otro principal del pueblo. El motivo: debían a Francisco del Castillo y a Cristóbal de Escalante, diezmeros mayores del corregimiento de Pacajes, treynta carneros de la tierra procedidos del diezmo de nuestras tasas. Gracias a la intermediación del protector de naturales Agustín de la Serna Alvarado y del corregidor, capitán Alonso López de Ayala, los caciques pudieron salir de prisión, no sin antes comprometerse a saldar su deuda con Juan de la Barreda, apoderado de los diezmeros. ${ }^{6}$ Nuevamente aquí, como en el caso de San Andrés y Santiago de Machaca, los rebaños de llamas fueron los recursos sacrificados para saldar deudas con españoles. En el escenario surandino, ya no resultaba extraño que los pagos se efectuaran en ganado; muy probablemente los diezmeros utilizaran esas 30 llamas para trasladar los bienes transables recolectados como diezmos o en negocios vinculados al acarreo de esas mercancías entre los centros de producción y consumo del sur andino.

Otro protagonista del ya referido remate de las especies de 1606, don Juan Camaqui, cacique de Caquiaviri y llavero de la caja de comunidad del 
pueblo, aparecería también en junio de 1610 saldando la deuda de 100 pesos corrientes de Gerónimo Condori, tributario de San Andrés de Machaca, con los jesuitas de La Paz. ${ }^{7}$ Entre ambos episodios, en Potosí en febrero de 1607 registramos una carta de obligación de pago dada por un grupo de autoridades menores de Caquiaviri, formado por don Domingo Pirca (segunda persona y principal del ayllu Yrapi de hurinsaya), don Francisco de Toledo (segunda persona, ayllu Guayba de hanansaya) y don Diego Paycho (segunda persona, ayllu Tuso de hanansa$y a$ ). Se comprometían a pagar 17 llamas a Blas de Caravajal por raçon de que el dicho Blas de Caravajal nos a dado e pagado 102 pesos de plata corriente, a razón de 6 pesos cada una. ${ }^{8}$ Resulta curioso que el escribano haya protocolizado esta operación como una obligación de pago, toda vez que los principales de Caquiaviri estaban vendiendo sus llamas a Caravajal. La formulación de la escritura, en cambio, hace aparecer a los principales como compradores de dinero, posible evidencia de una modalidad de acceso a la mercancía-dinero a partir de la mercantilización de los recursos nativos. Quizás la obligación encubriera un préstamo con garantía prendaria o en especie, la que se estaba formalizando en ese momento.

¿Qué conclusiones preliminares podemos obtener en relación con el manejo del ganado? Indagando las referencias al ganado en las crónicas, John Murra (1999 [1955]:85-86) enfatizó su rol como fuente de recursos en la época colonial. Sugería que, muy probablemente, los pastores pudieron pagar tributos en dinero mucho más fácilmente que los agricultores, sea mediante la venta de algunos animales para alimentar la población urbana o alquilándolos como bestias de carga en la nueva economía minera y comercial. Por lo complejo de este planteo, sugerimos que, además del valor de cambio que el ganado contenía para su venta en el mercado, también podía funcionar como medio de pago en sí mismo. Ya vimos cómo en 1607 los caciques de Caquiaviri extrañamente "pagaron" 17 llamas por 102 pesos corrientes, y en 1610 los caciques de Callapa cancelaron una deuda con los diezmeros "pagando" 30 llamas.

Thierry Saignes (1987b) también tuvo en cuenta el potencial productivo de los repartimientos de puna para sugerir una capacidad de gestión diferencial de los recursos, aunque no todos respondieron a este patrón. Nuestra exposición corrobora esa hipótesis, ya que los caciques principales de Santiago de Machaca y de Callapa, por un lado, y las autoridades menores de Caquiaviri, por el otro, tuvieron que volcar parte de los rebaños (propios y/o colectivos) al mercado. Incluso en San Andrés de Machaca observamos situaciones bien divergentes, ya que mientras algunos pudieron acumular y gestionar recursos ganaderos, otros tuvieron problemas para pagar sus tributos. ${ }^{9}$ El período 1590-1610, coyuntura que puso a prueba los pilares del orden toledano, arrojó pues un saldo disparejo en el corregimiento de Pacajes.

\section{Entre las deudas y la cárcel pública (1610-1630)}

¿Cuál era el destino de las autoridades étnicas que no lograban responder a las cargas coloniales? Tras registrar los retrasos, generalmente los corregidores intimaban a los caciques al pago de sus deudas; al no verificarse, disponían el embargo de los bienes de los caciques para rematarlos "en almoneda pública" para obtener el líquido necesario para cancelar los tributos rezagados. Pero si incluso así no se lograban cubrir las deudas, la cárcel pública de la ciudad fue el destino ulterior de muchos caciques, tal como sucedió con don Felipe Chocata de Callapa en 1610.

En enero de 1615, Isidro de Pisa Saavedra, notable vecino paceño y alcalde ordinario al año siguiente, se presentó ante Juan de Salazar, corregidor de Omasuyos, exigiendo la entrega del cacique de Pucarani, quien adeudaba las tasas de especies rematadas en el vecino. Salazar frenó esta demanda, ya que no ay cacique ninguno en la parcialidad de hurinsaya que son los que devian pagar las comidas que poderle entregar porque don Felipe Halanoca cacique principal es muerto en la villa de Potosi. Y su governador don Bernabe Aroquipa murio en este pueblo de la peste. Debido a esto, el corregidor ordenó a don Diego Mamani Guanca y a don Juan Guanca, alcaldes del pueblo, que trajeran al khipucamayoq para que diera cuenta de los rezagos exigidos; los alcaldes explicaron que a años que no a avido quipocamayo en la dicha parcialidad por estar tan perdida y rematada. ${ }^{10} \mathrm{Si}$ bien el demandante no logró cumplir su cometido, los caciques de Pucarani tampoco pudieron saldar sus deudas y terminaron en prisión. Asimismo, corroboramos la continuidad del cargo de khipucamayoq como responsable de la contabilidad de los tributos (de la Puente Luna y Curatola Petrocchi 2013).

¿Cómo sortear el fuego cruzado de las deudas y la cárcel? En agosto de 1630, don Juan Chota, 
cacique de Achacachi hanansaya (Omasuyos) y doña Francisca Choque, viuda de don Felipe Marca, cacique de Julloma (Pacajes), vendieron dos propiedades inmuebles al mercader Juan López de Silva, al precio de 150 y 125 pesos corrientes, respectivamente. Junto a su esposa, María Capcome, el cacique de Achacachi vendía en La Paz

un galpon grande con sus paredes cubierto de madera y ycho que mis padres edificaron en esta çiudad en la rancheria de los yndios del dicho pueblo de Achacache que son los que hacian mita a esta ciudad y se les avia señalado por esta çiudad en tiempo que haçian la dicha mita en ella que linda con casas de la una parte de doña Maria de Ganboa y de la otra con casas de don Juan Queste el Viejo y otros linderos

Don Juan entregaba en el acto 27 pesos de contado, ya que el resto correspondía a una deuda que el cacique había contraído con el mercader abra tiempo de dos años para ayuda a pagar sus tasas y una yegua de camino en 23 pesos con que se ajustaren los dichos 150 pesos. ${ }^{11}$ Por su parte, la viuda del cacique de Julloma vendía, con asistencia del capitán Juan de Tablares Cuello, receptor familiar del Santo Oficio, un galponçillo que tiene dos aposentos y otro descubierto que son las paredes y la madera (...) en la perroquia de Sancta Barvara linde con casas de los yndios del pueblo de Calacoto por un lado y otros linderos. ${ }^{12}$

El recurso al préstamo y a la enajenación de bienes propios de los caciques (en este caso, galpones ubicados en los barrios indígenas de La Paz) para cumplimentar el pago de los tributos resultó un salvoconducto para evitar la cárcel (Morrone 2011). Distinta fue la suerte de don Baltasar Guamani, cacique principal de Guaqui, quien en septiembre de 1631 se hallaría preso en la cárcel de La Paz. El corregidor de Pacajes, capitán don Joseph Márquez de Mansilla, no solo lo había encarcelado por adeudar los tributos, sino que también embargó sus bienes, en particular cierta cantidad de vacas cargas de chuño y otras cosas que tenia para mi sustento, según declaró el cacique. Guamani solicitó al general don Antonio de Barrasa y Cárdenas, corregidor de Caracollo y encomendero de Guaqui, una carta de pago,

en la qual confeso aver reçevido del capitan don Joseph Marques de Mançilla corregidor suso dicho y de los caçiques llaveros y caxas de comunidad del dicho pueblo de Guaqui por mi mano mil dosçientos pesos de a ocho reales por quenta de los tributos que uvo de aver y le perteneçen de su renta de los tercios de San Juan y Navidad del año pasado de seisçientos treinta de los quales se dio por contento y entregado (...) y que no le di ni pague los dichos pesos y le soy verdadero deudor dellos por cuia razon me obligo de se los dar e pagar (...) en ocho meses cumplidos primeros siguientes (...). ${ }^{13}$

No era esta la primera oportunidad en que don Baltasar Guamani terminaba en prisión. En 1618 don Gabriel Gómez de Sanabria, fiscal de la Audiencia comisionado para el reclutamiento de la mita de Oruro, había encarcelado a varios caciques del corregimiento de Pacajes por no cumplir con la leva exigida; don Baltasar Guamani había sido uno de ellos, aunque consiguió la libertad de la mano de don Gabriel Cusi Quispe, cacique principal de Caquiaviri y referente político regional del momento. ${ }^{14}$

En efecto, el encarcelamiento solo agravaba la situación de los caciques: desde prisión no podían articular las redes necesarias para garantizar el pago de los tributos y el entero de las cuotas mitayas, como así tampoco podían poner en marcha los circuitos productivos, redistributivos y rituales que encabezaban en tanto líderes colectivos. Con escasos recursos disponibles, no siempre podían obtener las fianzas requeridas para su excarcelación. Este círculo vicioso retroalimentaba, asimismo, la endémica disminución de la población tributaria, quienes emprendían periplos migratorios de distintas escalas para librarse de las cargas coloniales en sus pueblos de origen. Las primeras décadas del siglo XVII representaron, en efecto, un verdadero desafío para la continuidad de muchos caciques al frente de sus repartimientos.

\section{Reproducción y legitimidad en peligro: posibles derivaciones analíticas}

A lo largo de este trabajo nos propusimos transitar los senderos recorridos por algunos caciques de Pacajes y Omasuyos, siguiendo la propuesta analítica de Thierry Saignes según la cual las capacidades de reacción de los caciques surandinos divergieron en función del grado de control de 
recursos provenientes de las economías nativas, y que estos factores, a su vez, impactaron en su capacidad de concitar legitimidades. Los episodios presentados aquí se ubican en esa línea. En efecto, varios caciques debieron rematar sus rebaños $(y$, en algunos casos, propiedades inmuebles urbanas y rurales) para saldar deudas y rezagos, lo que atentaba contra la reproducción biológica y social de los ayllu y reducía la capacidad de articulación de circuitos comerciales, limitando sus márgenes de acción en el "espacio del trajín". Al mismo tiempo, si el cumplimiento de la mita potosina ya restaba potencia productiva a las unidades domésticas, el drenaje de mano de obra en estancias de españoles y en otros servicios personales y el ausentismo agravaban la situación. Acorralados por estas circunstancias, no pocos caciques sufrieron el embargo de sus bienes y, como corolario de sus desventuras, la prisión. Tal como confesaba un cacique en 1601, rompiendo en llanto ante un jesuita:

Padre, yo estoy obligado á enterar treinta $\mathrm{y}$ un indios, y destos há seis meses que me faltan diez y seis, y cada semana los he enterado y pagado ciento veinte $y$ seis pesos en alquilarlos, y para esto he vendido una mula que tenia, mis carneros $\mathrm{y}$ mis vestidos que tenia, $\mathrm{y}$ he buscado plata prestada, echado derrama entre mis indios; y no teniendo remedio para entregar los indios, la semana pasada empeñé una hija que tengo, á un español, porque me prestase sesenta y cuatro pesos que me faltaban, y la semana que viene, no sé qué hacerme, sino ahorcarme (Torres de Mendoza 1865;VI:159-160).

A modo de balance, podemos esbozar un circuito de retroalimentación negativa entre la capacidad de control y asignación de recursos y la legitimidad cacical. La reducción de la masa tributaria impedía que los caciques garantizaran la mediación del dominio colonial; el retraso en el pago del tributo y en el entero de la mita expresaban, en gran medida, un drenaje de recursos nativos hacia la esfera mercantil, lo cual impactaba de lleno en la legitimidad, ya que el cacique no podría cumplir con una de sus funciones centrales, es decir, garantizar la reproducción social de los ayllu. Con su autoridad puesta en jaque, el cacique vería desgranarse los pactos reciprocitarios tramados entre los ayllu, cuyos miembros no encontrarían atadura alguna para avalar esa autoridad venida a menos (o mal avenida). Debido a que no contamos con documentación para ilustrar las respuestas de los miembros de los ayllu frente al desgranamiento de la autoridad de sus caciques, nos movemos aquí en el plano de las hipótesis.

En función de lo expuesto, volvamos sobre el título de nuestro trabajo. ¿Qué significa que no todos los caciques hayan sido mallku? En su Vocabulario de la Lengua Aymara, el padre Ludovico Bertonio (1984;II,212,220 [1612]) establecía las siguientes asociaciones:

Mallco vel Mayco: Cacique, o señor de
vasallos. Mallcokhatha ${ }_{3}$ khe: Venir a ser
señor, o cacique. (...) Mayco: Señor de
vasallos. En otros pueblos dizen Mallco.
Maycokhatha ${ }_{3}$ khe: Venir a ser Mayco el
que no lo era. Maycochatha: Hazer lo que
sea o elegirle y nombrarle. (...) Maycoña,
vel Mayco cancaña: El señorio. Mando,
reynado.

Desde la temprana conquista, los españoles asociaron las estructuras andinas del poder a las categorías del lenguaje político monárquico vigente en sus reinos de origen. Para uniformar los distintos niveles de autoridad en las sociedades andinas, conquistadores, cronistas y funcionarios hispanizaron la voz arawak kassequa como "cacique" y la homologaron al quechua kuraka y al aymara mallku. Ya avanzado el proceso colonizador, registramos en la documentación la incorporación del adjetivo "principal" para diferenciar a los máximos representantes legítimos (y cabezas censales) de los colectivos étnicos de otras figuras de menor autoridad; finalmente, el tercer componente "gobernador" daba cuenta del efectivo ejercicio del cargo en cuestión, toda vez que muchos caciques no gobernaban o que muchos gobernadores no eran caciques. De este modo, obtenemos la clásica fórmula de "cacique principal y gobernador", que por recurrente no siempre ha sido problematizada (Díaz Rementeria 1977).

Pero esta ya clásica descripción terminológica no termina de abarcar el conjunto de transformaciones políticas que registramos en la región de estudio. En trabajos anteriores propusimos considerar las trayectorias de construcción, reproducción y desgranamiento del liderazgo étnico como un proceso 
conjunto, caracterizado tanto por el encumbramiento de unos pocos caciques con gran poder económico y relacional, capaces de articular redes mercantiles y accionar en la justicia colonial, como por el abroquelamiento de otros caciques de menor porte bajo el amparo de los primeros, devenidos en "escudos políticos" (Morrone 2011, 2013). De este modo, si bien todos ejercían el cargo de cacique, ese cargo no se traducía siempre en un liderazgo efectivo en términos de concitar legitimidades y responder exitosamente ante el desafío de la intermediación política. Esta interpretación se ofrece a condición de ser contrastada con la evidencia empírica resguardada en los fatigosos archivos hispanoamericanos. A la espera de futuros estudios, valgan aquí un conjunto de reflexiones a manera de balance.

¿Qué características comparten las situaciones analizadas aquí? La situación de estos caciques ilustra otra cara de la intermediación política. Segundas o terceras líneas de caciques, caciques menores o de repartimientos con menor control de recursos, principales al nivel del ayllu (Espinoza Soriano 1987; Jurado 2008): se trata de figuras con autoridad larvada o truncada, apenas emergente en el registro documental. ${ }^{15}$ Sus caminos fueron bien distintos a los transitados por los "caciques exitosos", sus liderazgos mucho más débiles y sus huellas en el registro documental mucho menos profundas. Por eso resulta más dificultoso historizar estas trayectorias, aunque demos con ellas entre protocolos notariales y expedientes judiciales; de hecho, proponemos una relación directa entre el escaso potencial político de estos caciques y su menor (o casi nula) visibilidad documental.

Estos caciques de menor porte, quienes terminaron en prisión o en la pobreza, con sus poblaciones huidas y sus tributos rezagados, constituyen el revés de la trama de aquellas grandes figuras de liderazgo; presentar sus desventuras pone a prueba, metodológicamente, el "modelo cacical mercantil" y las "estrategias de reacomodamiento", en la medida en que no todos los caciques pudieron articular ese tipo de relación social ni establecer ese tipo de vinculaciones con la "esfera española". Más bien, el abroquelamiento de caciques menores muestra otra de las variaciones y ambigüedades que encarnaron los caciques andinos en las instancias de mediación política en los Andes Meridionales (Platt 1982; Stern 1987).

Por otro lado, y si nuestra línea de análisis es adecuada, nos encontraríamos ante un matiz, un "signo de pregunta" respecto del planteo de
Saignes (1987b) sobre el "éxito" de los caciques altiplánicos para enfrentar el dominio colonial. Por un lado, presentamos aquí algunos episodios protagonizados por caciques de puna de "menor valía" que optaron por (o no tuvieron otra opción que) escudarse detrás de otros que respondieran por ellos frente a las autoridades españolas. Por otro lado, incluso dentro de un mismo pueblo de reducción, registramos ambas situaciones: en San Andrés de Machaca, don García Guanaco resultó altamente beneficiado por su participación en los mercados paceños, mientras que sus colegas de la década de 1590 debieron vender rebaños para evitar rezagos. Mientras tanto, en Caquiaviri, contrastamos los desiguales desempeños del renombrado don Gabriel Cusi Quispe y del endeudado don Juan Camaqui.

Ahora bien, ¿hasta qué punto puede resultar analíticamente operativo el par "éxito/fracaso" con el que se han interpelado las trayectorias de los caciques coloniales? Quizás uno de los principales condicionantes del campo historiográfico radique en la propia formulación del esquema interpretativo, ya que la dicotomía "éxito/fracaso" se inscribe en la misma lógica de la economía de mercado implementada por el dominio colonial en el mundo andino a partir del siglo XVI. Establecidas las nuevas reglas de juego, el grado de "adaptación selectiva" de los actores sociales en cuestión determinará el tipo de trayectoria a desplegar. De limitarse el análisis a determinar el nivel de "éxito" o "fracaso" de tal o cual cacique, podríamos caer en interpretaciones maniqueas y extremadamente enfocadas en la acción individual. En cambio, un abordaje más sensible a los contextos específicos que condicionaron la acción de los caciques podría echar luz sobre la puesta en práctica de múltiples estrategias.

En este sentido, ¿qué relaciones podemos establecer entre las trayectorias efectivamente seguidas por los caciques y sus respectivos "puntos de partida"? ¿Será que no todos tuvieron las mismas oportunidades para "amasar un fondo de poder" (Sahlins 1979:275 [1963]) como mecanismo para amplificar las reciprocidades entre sus ayllu y habilitar mayores márgenes de acción? ¿Qué factores intervinieron para que algunos lo lograran y otros no? ¿De qué capitales dispusieron (y, eventualmente, acumularon o resignaron) en el escenario político local? Las características de un mismo contexto podrían explicar, en este sentido, cómo y por qué algunos caciques se proyectaron hacia el encumbramiento, al tiempo que otros, más sometidos a 
las contingencias, quedaron asociados al colectivo de ayllu; no obstante, estos últimos fueron claves en el armado de las redes políticas a escala local. Así, unos y otros bien pudieron estar asociados en torno a cadenas de mando escasamente registradas (o incluso refractadas) por la documentación, tanto en sentido vertical (grandes caciques regionales, caciques de repartimientos de segunda línea, alcaldes y autoridades menores de mitad o de ayllu) como horizontal (redes de parentesco biológico y ritual, patronazgo, alianzas circunstanciales). ¿En qué consistían esos vínculos y cómo se tramaban? ¿En torno a qué prácticas e intereses se integraban esos encadenamientos? ¿En qué circunstancias funcionaban y cuáles no, y por qué? ¿Pudieron haberse conformado facciones alineadas en torno a grandes líderes rivales? Este panorama (hipotético, por el momento) de alianzas y cadenas de mando operadas entre caciques de distinta jerarquía se complica aún más si incorporamos la variable interétnica, toda vez que la interacción con miembros del segmento dominante de la sociedad colonial (autoridades, mercaderes, curas doctrineros) también constituía un factor clave para la construcción de legitimidades y reproducción del liderazgo nativo.

En efecto, los márgenes de acción de los caciques andinos frente a los desafíos impuestos por el dominio colonial distaron de responder a un único patrón de desarrollo. Nuestros avances de investigación apuntan a establecer los procesos combinados de estructuración y reproducción de liderazgos étnicos, entendiendo que sus trayectorias (casi microhistóricas) abonan al entendimiento del funcionamiento del sistema colonial, cuya reproducción no fue viable sin el armado de nudos locales de poderes intermedios. Los caciques de menor porte trabajados aquí complican el panorama político regional, ya que muestran otras facetas de la intermediación política; facetas menos renombradas, menos "exitosas", pero no por ello menos relevantes.

\section{Agradecimientos}

Una versión preliminar de este trabajo fue presentada en el IX Congreso Internacional de Etnohistoria, organizado por la Universidad de Tarapacá en Arica, Chile, del 11 al 14 de noviembre de 2014. Agradecemos los comentarios y recomendaciones que las colegas Roxana Boixadós, María Carolina Jurado, Teresa Vergara Ormeño y Marina Zuloaga Rada nos hicieran en aquella oportunidad, como así también a los evaluadores de Diálogo Andino.

\section{Referencias Citadas}

Assadourian, C.S.

1987 Intercambios en los territorios étnicos entre 1530 y 1567, según las visitas de Huanuco y Chucuito. En $\mathrm{La}$ Participación Indígena en los Mercados Surandinos, Harris, Larson y Tandeter (comps.), pp. 65-110.

Bertonio, L.

1984 [1612] Vocabulario de la Lengua Aymara. Ceres, Cochabamba.

Bourdieu, P.

2007 [1994] Razones Prácticas. Sobre la teoría de la acción. Anagrama, Barcelona.

Choque Canqui, R.

1987 Los caciques aymaras y el comercio en el Alto Perú. En La Participación Indígena en los Mercados Surandinos, Harris, Larson y Tandeter (comps.), pp. 357-377.

Choque Canqui, R.

1993 Sociedad y Economía Colonial en el Sur Andino. Hisbol, La Paz.

Cutrera, M.L.

2014 Subordinarlos, Someterlos y Sujetarlos al Orden. Rosas y los indios amigos de Buenos Aires entre 1829 y 1855. Teseo, Buenos Aires.

De la Puente Luna, J.C. y M. Curatola Petrocchi

2013 El Quipu Colonial. Estudios y materiales. PCUP, Lima.
Díaz Rementeria, C.F.

1977 El Cacique en el Virreinato del Perú. Estudio históricojurídico. Universidad de Sevilla, Sevilla.

Espinoza Soriano, W.

1987 El señorío de Ayanca en el reino Lupaca. Siglos XVXVII. Diálogo Andino 6: 46-77.

Gisbert, T.

1992 Los curacas del Collao y la conformación de la cultura mestiza andina. En 500 Años de Mestizaje en los Andes, Hiroyasu Tomoeda y Luis Millones (eds.), pp. 52-102. National Museum of Ethnology, Osaka.

Glave, L.M.

1989 Trajinantes. Caminos indígenas en la sociedad colonial. Siglos XVI/XVII. Instituto de Apoyo Agrario, Lima.

Glave, L.M.

2007 Fray Alonso Granero de Ávalos y los naturales andinos: debates sobre el destino de la sociedad colonial a inicios del siglo XVII. Cuadernos Interculturales 8: 15-50.

Harris, O.; Larson, B. y Tandeter, E. (comps.)

1987 La Participación Indígena en los Mercados Surandinos. Estrategias y reproducción social, siglos XVI-XX. Ceres, La Paz.

Jurado, M.C.

2008 Delineando a las 'segundas personas': autoridades étnicas desdibujadas en Charcas colonial. Un estudio de caso. Revista Andina 46: 193-210. 
Medinacelli, X.

2010 Sariri. Los llameros y la construcción de la sociedad colonial. IFEA/Plural, Lima/La Paz.

Monsalve Zanatti, M.

1994 Comentario al artículo de Roberto Choque Canqui, “Una iglesia de los Guarachi en Jesús de Machaca (Pacajes-La Paz)”. En La Venida del Reino. Religión, evangelización y cultura en América. Siglos XVI-XX, Gabriela Ramos comp. Centro Bartolomé de Las Casas, Cuzco.

Morong, G.

1999 Textualidad hispana y dominación colonial: la construcción de la legitimidad hispana por el dominio del Tawantinsuyu durante la administración toledana 1567-1572. Diálogo Andino 18: 91-120.

Morrone, A.J.

2011 Territorialidad y liderazgo étnico entre la reducción y la revisita: los caciques de San Pedro y Santiago de Chuquiabo (1573-1630). Revista Andina 51: 163-194.

Morrone, A.J.

2012 De "señores de indios" a nobles rentistas: los encomenderos de La Paz (1548-1621). Surandino Monográfico, Segunda Sección de Prohal Monográfico II (2). www.filo. uba.ar/contenidos/investigacion/institutos/ravignani/prohal/ mono.html

Morrone, A.J.

2013 Estrategias estatales y liderazgo étnico en el corregimiento de Pacajes (1538-1620). En Aportes Multidisciplinarios al Estudio de los Colectivos Étnicos Surandinos. Reflexiones sobre Qaraqara-Charka tres años después, Ana María Presta (ed.), pp. 242-272. IFEA-Plural, La Paz.

Morrone, A.J.

2014 Reconfiguración de alianzas políticas en contextos críticos: los caciques de San Andrés de Machaca (Pacajes, audiencia de Charcas, siglos XV-XVII). Boletín Americanista 68: $187-210$.

Murra, J.V.

1999 [1955] La Organización Económica del Estado Inca. Siglo XXI, México.

Núñez, L. y Dillehay, T.D.

1978 Movilidad Giratoria, Armonía Social y Desarrollo en los Andes Meridionales: patrones de tráfico e interacción económica (ensayo). Universidad del Norte, Antofagasta.

Pease G.Y., F.

1992 Curacas, Reciprocidad y Riqueza. PCUP, Lima.

Platt, T.

1982 Estado Boliviano y Ayllu Andino. Tierra y tributo en el norte de Potosí. IEP, Lima.
Presta, A.M.

2013 Los valles mesotérmicos de Chuquisaca entre la fragmentación territorial yampara y la ocupación de los migrantes qaraqara y charka en la temprana colonia. En Aportes Multidisciplinarios, Presta (ed.), pp. 27-59.

Rivera Cusicanqui, S.

1978 El mallku y la sociedad colonial en el siglo XVII: el caso de Jesús de Machaca. Avances 1: 7-27.

Sack, R.D.

1986 Human Territoriality. Its Theory and History. Cambridge University Press, Cambridge.

Sahlins, M.D.

1979 Hombre pobre, hombre rico, gran hombre, jefe: tipos políticos en Melanesia y Polinesia". En Antropología Política, J.R. Llobera (comp.), pp. 267-288. Anagrama, Barcelona.

Saignes, $\mathrm{T}$.

1984 Las etnias de Charcas frente al sistema colonial (Siglo XVII). Ausentismo y fugas en el debate sobre la mano de obra indígena, 1595-1665. Jahrbuch für Geschichte von Staat, Wirtschaft und Gesselschaft Lateinamerikas 21: 27-75.

Saignes, T.

1987a Ayllus, mercado y coacción colonial: el reto de las migraciones internas en Charcas (siglo XVII). En: $L a$ Participación Indígena en los Mercados Surandinos, Harris, Larson y Tandeter (comps.), pp. 111-158.

Saignes, $\mathrm{T}$.

1987b De la borrachera al retrato: los caciques andinos entre dos legitimidades (Charcas). Revista Andina 5 (1): 130-170

Spalding, K.

1974 De Indio a Campesino. Cambios en la estructura social del Perú colonial. IEP, Lima.

Stern, S.J.

1986 [1982] Los Pueblos Indígenas del Perú y el Desafío de la Conquista Española. Huamanga hasta 1640. Alianza, Madrid.

Stern, S.J.

1987 La variedad y ambigüedad de la intervención indígena andina en los mercados coloniales europeos: apuntes metodológicos. En: La Participación Indígena en los Mercados Surandinos, Harris, Larson y Tandeter (comps.), pp. 281-312.

Thomson, $\mathrm{S}$.

2006 Cuando solo reinasen los indios. La política aymara en la era de la insurgencia. Muela del Diablo-Aruwiyiri, La Paz.

Torres de Mendoza, L. (dir.)

1865 Colección de Documentos Inéditos Relativos al Descubrimiento, Conquista y Colonización de las Posesiones Españolas en América y Oceanía. Imprenta de Frías y Compañía, Madrid.

\section{Notas}

1 Empleamos el concepto de "trayectoria" entendido como la serie de las posiciones sucesivamente ocupadas por un mismo agente (o un mismo grupo) en un espacio en sí mismo en movimiento y sometido a incesantes transformaciones (Bourdieu 2007:82 [1994]).

2 Archivo Histórico de Potosí (AHP), Escrituras Notariales (EN) 24, ff. 1803r-1804v: Pedro de Venegas. Archivo y Biblioteca Nacionales de Bolivia (ABNB), Expedientes Coloniales (EC) 1606-2. Cf. Morrone 2014.
3 AHP EN 21, ff. 1712v y 1789v-1790r: Juan Gutiérrez Bernal. El carache o "caracha" es el nombre utilizado en la región para la sarna (Bertonio 1984;II:37 [1612]). Santiago de Mamañeca era el nombre que, en algunos documentos, recibía el pueblo de Santiago de Machaca.

4 ABNB EC 1606-2, f. 2 r.

5 ABNB EC 1607-2. Este expediente forma parte de una serie de visitas llevadas a cabo en 1607 por el capitán Ciancas en las estancias ganaderas de españoles en varios pueblos de la cuenca norte del lago Titicaca. 
6 Archivo Histórico Municipal de La Paz (AHM), Registro de Escrituras (RE) 2, ff. 315r-317v: Sebastián de Córdoba. 7 AHM RE 2, ff. 177v-178v: Sebastián de Córdova. 8 AHP EN 40, ff. 215v-216v: Felipe de Godoy.

9 Otro mecanismo empleado por algunos caciques fue transferir buena parte de los recursos (propios y colectivos) a instituciones religiosas, bajo la forma de capellanías o donaciones piadosas. De este modo, parte de la dotación de recursos podía ser salvaguardada en contextos de aumento de exacciones coloniales o crisis demográficas (Monsalve Zanatti 1994:288-293).

10 Archivo de La Paz (ALP), Cajas Reales (CR) 1615 Caja 2 Documento 1. Isidro de Pisa Saavedra era miembro de la alta sociedad paceña de principios del siglo XVII; estaba casado con doña María de Céspedes y Torres, hija de don Agustín de Espinosa y Céspedes, encomendero en segunda vida de Laja, y de doña Isabel Chirinos, de la familia encomendera de Pucarani hanansaya (corregimiento de Omasuyos). Cf. Glave 2007 y Morrone 2012.

11 ALP, Registro de Escrituras (RE), Caja 21, Legajo 34, ff. 346r-347v: Juan López Mexia.
12 ALP RE C21 L34, ff. 374r-375v: Juan López Mexia. 13 ALP RE C21 L35, ff. 719v-720v: Pedro de Manzaneda. 14 Archivo General de Indias, Audiencia de Charcas, Legajo 52, ff. 794r-802v. Cf. Glave 2007 y Morrone 2013.

15 La forja de la expresión "liderazgos étnicos truncados" no me pertenece de manera exclusiva. En 2009, María Laura Curetra me propuso realizar un trabajo en colaboración para analizar lo que denominamos "el caso Yanquelén". La idea general consistía en analizar las circunstancias específicas que ponían en tensión el lugar de los caciques de la frontera bonaerense durante la década de 1830, en pleno gobierno de Juan Manuel de Rosas. Queríamos analizar las trayectorias de aquellas autoridades étnicas que no pudieron resolver las contradicciones emanadas de su posición intermediaria. Para ello, propusimos seguir los pasos del cacique rankülche Santiago Yanquelén. Su interés por congraciarse con el gobernador fue aislándolo de sus seguidores, quienes cuestionaron su legitimidad y eventualmente lo abandonaron. Yanquelén fue asesinado por grupos rankülche en 1838. Si bien nunca escribimos ese trabajo, Cutrera (2014:162-175) profundizó el "caso Yanquelen" en el marco de su tesis doctoral. 
